\title{
Relação entre a Qualidade dos Sites das Prefeituras e o Nível de Divulgação da Remuneração dos Servidores Públicos Municipais
}

\section{Relationship between Site Quality and the Disclosure Level of the Public Employees Remuneration}

\author{
Alex Eckert \\ Doutor em Administração - UCS/PUCRS \\ Professor da Universidade de Caxias do Sul - UCS \\ R. Francisco Getúlio Vargas, 1130, Caxias do Sul - RS - Brasil \\ CEP: $95.070-560$ \\ E-mail: aeckert@ucs.br
}

\author{
Thamires Matté Toniolli \\ Graduada em Ciências Contábeis - UCS \\ Bacharel pela Universidade de Caxias do Sul - UCS \\ R. Francisco Getúlio Vargas, 1130, Caxias do Sul - RS - Brasil \\ CEP: $95.070-560$ \\ E-mail: tmtoniolli@gmail.com
}

\author{
Marlei Salete Mecca \\ Doutora em Engenharia da Produção - UFSC \\ Professora da Universidade de Caxias do Sul - UCS \\ R. Francisco Getúlio Vargas, 1130, Caxias do Sul - RS - Brasil \\ CEP: 95.070-560 \\ E-mail: msmecca@ucs.br \\ Roberto Biasio \\ Doutor em Administração - UFRGS \\ Professor da Universidade de Caxias do Sul - UCS \\ R. Francisco Getúlio Vargas, 1130, Caxias do Sul - RS - Brasil \\ CEP: 95.070-560 \\ E-mail: rbiasio@ucs.br
}




\title{
Resumo
}

A transparência das contas públicas é um dos principais pilares do direito democrático, sancionado principalmente pelas leis de acesso à informação, da transparência e de responsabilidade fiscal. Portanto, a qualidade das informações divulgadas nos sites é essencial para a compreensão do cidadão, inclusive as informações da remuneração dos servidores que representam parte significativa das despesas públicas. Assim, este estudo buscou verificar como pode ser avaliada a qualidade das informações dos sites das prefeituras da Serra Gaúcha, especialmente em relação à divulgação da remuneração de seus servidores. Para tanto, a metodologia utilizada quanto aos procedimentos técnicos foi o estudo de caso múltiplo e a pesquisa documental, de natureza descritiva, com análise qualitativa e quantitativa. Os resultados indicam que não há relação entre a qualidade das informações e a divulgação completa da remuneração. Além disso, foi evidenciado que as informações divulgadas necessitam ser aprimoradas para serem úteis aos cidadãos, principalmente no que concerne à atualização dos dados. Com relação aos salários, muitos municípios já divulgam essas informações, inclusive nominalmente, contudo ainda há grandes dificuldades no acesso a essas informações pela população.

Palavras-chave: Transparência; Acesso à informação; Contas públicas; Qualidade dos sites; Remuneração.

\begin{abstract}
The transparency of public accounts is one of the main pillars of democratic rights, especially sanctioned by the laws of access to information, transparency and fiscal responsibility. Therefore, the quality of information provided on the websites is essential for the understanding of people, including remuneration information of the servers that represent a significant part of public spending. In this sense, this study aims to evaluate how it can be evaluated the quality of information the websites of the municipalities of Serra Gaúcha, in Brazil, especially regarding the disclosure of the remuneration of their employees. Therefore, the methodology used on the technical procedures was the multiple case studies, descriptive, qualitative and quantitative analysis. The results indicate that there is no relationship between the quality of information and full disclosure of remuneration. In addition, the disclosures need to be improved to be useful to the population, especially as regards the update of data. With regard to wages, many municipalities already disclose this information. However, there are still great difficulties in access to this information by people.
\end{abstract}

Keywords: Transparency; Access to information. Public Accounts; Site quality; Remuneration.

\section{Introdução}

A transparência nas contas públicas já não se trata de uma novidade, visto que obteve maior reconhecimento a partir do advento da Lei Complementar n. 101, mais conhecida como Lei de Responsabilidade Fiscal (LRF), no ano de 2000. Com a aplicação da LRF na prática, surgiram outras normatizações como a Lei Complementar n. 131 em 2009.

Em seguida, no ano de 2011 foi promulgada a Lei n. 12.527, que assegura a qualquer cidadão o acesso às informações públicas, desde que não sejam sigilosas ou pessoais. Ao completar 3 anos de sua entrada em vigor, o acesso à informação somou 18,3 mil pedidos, somente no Rio Grande do Sul, ao Tribunal de Justiça, governo do Estado, Assembleia 
Legislativa, Ministério Público e Tribunal de Contas do Estado, o que representa 17 pedidos por dia (CORREIO DO POVO, 2015).

Desde a publicação da Lei de Acesso à Informação surgiram questionamentos quanto aos tipos de informações devem ser divulgadas: o que são consideradas informações sigilosas ou pessoais? O salário dos servidores, pago com recursos públicos, pode ser considerado uma informação pessoal? Mesmo com a divulgação de outras normas que buscaram elucidar estas e outras questões, ainda assim causam controvérsia.

Por ser um assunto de interesse público, atraiu também a atenção da mídia. O colunista David Coimbra, por intermédio de um artigo de opinião intitulado "O salário público dos servidores" publicado no Jornal Zero Hora de 13 de julho de 2012, se mostrou contrário à divulgação nominal da remuneração dos servidores, devido aos constrangimentos e o risco à segurança que poderiam causar (COIMBRA, 2012).

Contudo, dois dias antes, a Revista Veja (2012) havia publicado em seu site a explanação da Advocacia Geral da União (AGU), o qual alega que a publicação dos salários é uma forma de defesa do direito democrático. Ainda argumenta que essa prática é comum em vários países, como Argentina, Canadá, Israel, Hungria, Peru, Chile e Estados Unidos e a omissão desses dados causaria uma grave lesão à ordem pública.

Gisele Craveiro, coordenadora do Colaboratório de Desenvolvimento e Participação da Universidade de São Paulo (USP), em reportagem publicada no Jornal Pioneiro de 11 de junho de 2015, declara que a lei brasileira de acesso à informação é uma das mais progressistas do mundo e uma das primeiras a determinar, expressamente, os dados em formato aberto (CRAVEIRO, 2015).

Portanto, no âmbito acadêmico e científico, a importância desse estudo se dá pela possibilidade de auxiliar no desenvolvimento de novas pesquisas a respeito do tema ou sobre aspectos relacionados. Além disso, há a perspectiva de apresentar aos acadêmicos e outros interessados a real situação dos municípios da região com relação ao que se observa na teoria. Por envolver a questão da Administração Pública poderá, inclusive, ser aproveitado em outras áreas do conhecimento como direito, ciências políticas, economia, dentre outras.

A relevância desse trabalho também se comprova sob o ponto de vista profissional, como uma alternativa de auto avaliação para os municípios e comparação com as cidades próximas, inclusive para o próprio Tribunal de Contas que é o órgão fiscalizador. Da mesma maneira, a realização desse estudo pode servir de subsídio para o conhecimento da sociedade em geral a fim de exercer seu direito de cidadania.

Assim, diante desse contexto, a presente pesquisa tem como objetivo verificar como pode ser avaliada a qualidade das informações dos sites das prefeituras da Serra Gaúcha, especialmente em relação à divulgação da remuneração de seus servidores, evidenciando em que medida existe um alinhamento entre estas duas variáveis. Pressupõe-se que aqueles sites com um nível maior de qualidade apresentem as informações completas acerca desta situação, conforme definido pela legislação vigente.

\section{Referencial teórico}

\subsection{Transparências, publicidade e accountability.}

O princípio da publicidade está previsto no caput do artigo 37 da Constituição Federal de 1988 como um dos princípios gerais da Administração. A publicidade, portanto, pode ser definida como uma atividade dirigida a tornar conhecido um fato, uma situação ou uma relação jurídica (LOUREIRO, 2012). Esse princípio deve compreender todos os atos da Administração Pública, sendo obrigatória a divulgação oficial para conhecimento, controle e início de seus efeitos, portanto essencial à sua eficácia (GOMES, 2012). 
O princípio da transparência, por sua vez, consiste no acesso público às informações dos documentos orçamentários, contábeis e financeiros (NASCIMENTO, 2012). Há que se registrar que a expressão transparência, não se confunde com o princípio da publicidade, pois não basta a divulgação dos atos e dos números da gestão, é necessário que seja feita de forma que a população possa interpretá-los (CRUZ et al., 2014). A transparência é um conceito mais amplo, composta por três elementos: a publicidade, a compreensibilidade e a utilidade para decisões (PLATT NETO et al., 2013).

Já o conceito de accountability, próprio do sistema anglo-saxão, parece identificar-se bastante com a ideia de responsabilidade fiscal. Contudo, sua tradução é bastante difícil, mesmo nos estudos aprofundados, ainda não foi encontrado termo satisfatório no português (MENDES, 2012). Um dos ingredientes básicos da accountability é a transparência nas ações governamentais, que tem sido citada como capaz de contribuir para redução da corrupção (SACRAMENTO; PINHO, 2007).

O desenvolvimento de mecanismos de controle e participação tais como as iniciativas em prol da accountability, tem representado um grande avanço para a democracia, apesar disso, muitos desafios permanecem no processo de fortalecimento da accountability (VEGA; BERNAL, 2015).

Tendo como base planejamento, transparência e controle, a Lei Complementar n. 101 de 04 de maio de 2000, conhecida como Lei de Responsabilidade Fiscal (LRF) surgiu como um dos principais instrumentos reguladores das finanças públicas, objetivando uma melhor gestão dos gastos e uma maior responsabilidade de seus administradores (ROGERS; SENA, 2007).

A Lei Complementar n. 131 de 27 de maio de 2009, conhecida como "Lei da Transparência", alterou a LRF reforçando a transparência. O novo texto, além de incentivar a participação popular na formulação do orçamento, determina a divulgação das informações sobre execução financeira e orçamentária, em tempo real, por meios eletrônicos de acesso irrestrito (MENDES, 2012). Para satisfazer a exigência legal, foram criados os chamados "Portais de Transparência", os quais deverão divulgar via Internet, as informações orçamentárias e financeiras exigidas pela LRF. (MATOS et al., 2013).

Com vigência a partir de 16 de maio de 2012, a Lei n. 12.527 conhecida como "Lei de Acesso à Informação" (LAI), de 18 de novembro de 2011, regula o acesso a informações no Brasil previsto nos artigos $5^{\circ}, 37^{\circ}$ e $216^{\circ}$ da Carta Magna (VELOSO, 2014). Para Cruz et. al (2014), o principal objetivo observado com a criação desta Lei é o de assegurar a gestão transparente da informação, propiciando amplo acesso, já que a LAI detalha que as informações devem ser disponibilizadas a qualquer interessado.

Para Casalino et al. (2013), um governo aberto pode contribuir para estabelecer uma cultura de participação e colaboração entre as principais partes interessadas, pois permite o aumento da transparência nos órgãos públicos, além de estimular melhorias nos serviços, inovações mais rápidas e fortalecer os direitos dos cidadãos. Nessas condições, esta lei tratase de um importante marco para a observância da publicidade como preceito geral e do sigilo como exceção (MENDES; BRANCO, 2014).

\subsection{Divulgação da remuneração dos servidores públicos}

As leis que tratam da transparência não determinam expressamente a divulgação nominal das informações atinentes à remuneração dos servidores, somente das despesas do órgão público, de forma genérica (BOZZETTO, 2014). Contudo, após a promulgação da Lei de Acesso à Informação, a União, os Estado e os Municípios, vêm promovendo, com o intuito de dar maior efetividade ao direito fundamental à informação, a publicação nominal dos vencimentos de seus agentes (PEREIRA, 2014). 
Para Bozzetto (2014), o Decreto n. 7.724 de 16 de maio de 2012 e a Resolução n. 151 de 05 de julho de 2012 do Conselho Nacional de Justiça (CNJ), ao regulamentarem a Lei 12.527/11, impuseram, administrativamente, a determinação de divulgação individualizada das remunerações dos servidores públicos, criando obrigações e restringindo direitos dos servidores públicos.

Pereira (2014) reitera e acrescenta que a lei, além de não contemplar a interpretação que lhe vem sendo dada, demanda compreensão em sentido oposto, pois considera que a remuneração dos servidores deve ser tratada como informação pessoal, podendo ser divulgada, contudo sem ser nominal. Para Bozzetto (2014) com base no direito constitucional, a LAI no artigo 31 e seus parágrafos, bem como no artigo $6^{\circ}$, III, dispõe expressamente sobre a proteção às informações pessoais.

O acesso dos cidadãos à informação a respeito dos atos da Administração Pública constitui movimento mundial. Pesquisa da Unesco revela que mais de140 países já adotam ou estão em processo de adoção de Lei de Acesso à Informação - LAI (VELOSO, 2014). A Suécia é considerada um país pioneiro em matéria de direito à informação com leis desde 1766. Na Europa, aliás, todos os países com mais de um milhão de habitantes possuem regulamentação com relação ao acesso à informação, o último deles foi a Espanha em 2013 (PEREIRA, 2014).

Nos Estados Unidos, o fortalecimento da Lei de Liberdade da Informação (Freedom of Information Act - FOIA) trouxe a redução da corrupção e o aumento da probabilidade de detectar atos de corrupção (CORDIS; WARREN, 2014). A partir das realidades dos países citados, dentre tantos outros que poderiam ser referidos, pode-se perceber que a preocupação de implementar um direito de acesso à informação sobre atos estatais não é, nem de longe, exclusiva do Brasil (PEREIRA, 2014).

A jurisprudência dos Tribunais Regionais Federais é divergente quanto à possibilidade de divulgação nominal da remuneração, ora permitindo, ora proibindo (BOZZETTO, 2014). Entretanto, o Supremo Tribunal Federal (STF) já havia reconhecido o direito à informação, admite ser legítimo o acesso a dados da remuneração titularizadas por servidores públicos, por serem informação de interesse coletivo ou geral (RAMOS, 2014). O STF reforçou sua decisão através da suspensão de liminar n. 630 de 30 de julho de 2012, cuja qual considera que:

Não cabe, no caso, falar de intimidade ou de vida privada, pois os dados objeto da divulgação em causa dizem respeito a agentes públicos enquanto agentes públicos mesmos; ou, na linguagem da própria Constituição, agentes estatais agindo "nessa qualidade" ( $\$ 6^{\circ}$ do art. 37$)$. E quanto à segurança física ou corporal dos servidores, seja pessoal, seja familiarmente, claro que ela resultará um tanto ou quanto fragilizada com a divulgação nominalizada dos dados em debate, mas é um tipo de risco pessoal e familiar que se atenua com a proibição de se revelar o endereço residencial, o CPF e a CI de cada servidor. No mais, é o preço que se paga pela opção por uma carreira pública no seio de um Estado republicano.

Ainda que o Supremo Tribunal Federal não possua, até o momento, nenhum pronunciamento posterior à entrada em vigor da LAI (em que a lei tenha sido examinada), em inúmeras liminares, deixou claro o entendimento que deverá ser adotado, em definitivo, pela Corte no sentido de que a divulgação nominal de vencimentos está em harmonia com a lei de regência da matéria e com a Constituição Federal (PEREIRA, 2014). 


\subsection{A qualidade da informação dos sites}

Muitos esforços têm sido feitos na tentativa de conceituar o que é uma informação adequada em um site, com qualidade. No entanto, ainda não há uma definição padrão (GONÇALVES; RICCIO, 2009). Mas, sabe-se que, para serem valiosas, as informações devem ter uma série de características essenciais: devem ser íntegras, precisas, atualizadas e coerentes com a finalidade para a qual são utilizadas (TURBAN; VOLONINO, 2013). Dessa forma, a informação deve ser disponível quando ela for necessária e com a melhor precisão possível (FOINA, 2013).

Problemas com a qualidade da informação são enfrentados por milhões de pessoas diariamente, quando buscam por informações online, seja em páginas disponíveis publicamente na Web, seja em bancos de dados especializados. Entre os problemas mais comuns está a omissão de materiais e, ainda a informação pode ter sido relatada de maneira incorreta, intencionalmente ou não, ou pode ter se tornado obsoleta (TURBAN; VOLONINO, 2013).

A internet oferece ao cidadão uma quantidade incomensurável de informações que, muitas vezes, são disponibilizadas sem que haja qualquer tipo de avaliação, o que pode vir a prejudicar o cidadão (MENDONÇA; PEREIRA NETO, 2015). A partir do aumento do interesse sobre a transparência pública advindo das leis de Acesso à Informação e da Transparência, busca-se pela qualidade das informações disposta nos sites governamentais, especialmente em portais da transparência, para aferir se as informações são claras o suficiente para serem consideradas, de fato, transparentes (SILVA; CARREIRO, 2014).

\section{Procedimentos metodológicos}

Quanto aos procedimentos técnicos adotados para a realização da pesquisa, destacase o estudo de caso que, para Gil (2010) consiste no estudo profundo e exaustivo de um ou poucos casos, de maneira que permita seu amplo e detalhado conhecimento. Já para Yin (2015), a necessidade da pesquisa de estudo de caso surge do desejo de entender fenômenos sociais complexos. Ainda em relação aos procedimentos técnicos, esse estudo ainda possui características de pesquisa documental. Para Cervo e Bervian (2002), nela são investigados documentos a fim de se poder descrever e comparar costumes, tendências, diferenças e outras características.

Em relação aos objetivos, o presente estudo é predominantemente descritivo. Uma pesquisa descritiva, para Marion et al. (2010), busca descrever um fenômeno ou uma população, para isso, o investigador observa, quantifica, descreve e classifica. Ao passo que, para Köche (2010), esse tipo de pesquisa estuda as relações entre variáveis de um dado fenômeno sem manipulá-las.

No tocante à abordagem do problema, o estudo é preponderantemente qualitativo. Para Marion et al. (2010), na pesquisa qualitativa busca-se caracterizar as dimensões, as variações, a importância e/ou o significado do fenômeno. Já para Minayo et al. (2002) esta pesquisa, nas ciências sociais, trabalha com o universo de significados, motivos, aspirações, crenças, valores e atitudes, o que corresponde a um espaço mais profundo das relações, dos processos e dos fenômenos que não podem ser somente quantificados.

Minayo et al. (2002) ainda acrescentam que os métodos qualitativos e quantitativos não se opõem, pelo contrário, se completam, pois a realidade abrangida por eles interage dinamicamente. Dessa forma, neste estudo, também são utilizadas características da abordagem quantitativa que, para Marion et al. (2010), é aquela em que o pesquisador reúne, registra e analisa dados numéricos, através do estudo de uma amostra, quantifica fatores e procura correlações estatísticas e probabilísticas. 
Dessa forma, primeiramente foi realizada a busca e análise da bibliografia acerca do tema, através da pesquisa em livros, periódicos, dentre outros. Concomitantemente, foi feita a identificação de quais municípios pertencem à região da Serra Gaúcha, por meio da busca em dados oficiais. O motivo pela escolha da região deve-se ao fato de ser uma região com destaque econômico, principalmente nos setores metal, mecânico, moveleiro e vitivinícola. Os 33 municípios da Serra Gaúcha selecionados de acordo com os dados do Corede Serra (AUNE, 2015), foram avaliados, em ordem decrescente de população, segundo dados do IBGE (2010), quanto à qualidade das informações publicadas em seus sites.

Após, a autora que liderou a pesquisa, em conjunto com os demais pesquisadores, avaliou a qualidade das informações dos sites das prefeituras estudadas através da utilização de uma escala, que variava de 0 a 10. Depois, essa mesma avaliação também foi realizada por um especialista de tecnologia da informação independente e, posteriormente por profissionais de tecnologia da informação dos municípios em estudo com relação à sua cidade.

\section{Apresentação e análise dos resultados}

A elaboração deste estudo foi realizada mediante duas etapas. A primeira consiste na avaliação da qualidade da informação dos sites dos municípios da Serra Gaúcha, e a segunda, a verificação nesses sites quanto à forma de divulgação da remuneração de seus servidores.

\subsection{Análises da qualidade da informação dos sites}

As avaliações foram realizadas pelos autores deste estudo, por um profissional de Tecnologia da Informação independente e por um profissional de Tecnologia da Informação de cada município. Com base nas três avalições, foi elaborado o Quadro 1 a seguir.

Quadro 1: Médias das avaliações por municípios 


\begin{tabular}{|c|c|c|c|c|}
\hline Municípios & 总 & 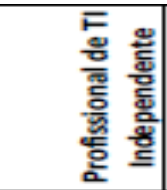 & 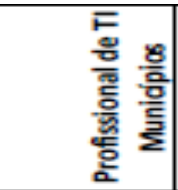 & Média \\
\hline Caxias do Sul & 8,14 & 8.43 & 9,29 & 8,62 \\
\hline Bento Gonçalves & 8.00 & 7.71 & 9,14 & 8,28 \\
\hline Farroupilha & 7.86 & 8.29 & 8,00 & 8,05 \\
\hline Garibaldi & 8,14 & 8.43 & 7,14 & 7,90 \\
\hline Flores da Cunha & 8,00 & 8.29 & 8,86 & 8,38 \\
\hline Carlos Barbosa & 7.43 & 7.43 & 7,57 & 7,48 \\
\hline Nova Prata & 7.43 & 7.71 & 9,43 & 8,19 \\
\hline Guaporé & 8.14 & 7.86 & 7,71 & 7,90 \\
\hline Veranópolis & 7.71 & 7.86 & 8,29 & 7,95 \\
\hline São Marcos & 7.00 & 7.57 & 6,00 & 6,86 \\
\hline Serafina Corrêa & 7.29 & 8.00 & 10,00 & 8,43 \\
\hline Antônio Prado & 7.86 & 8.14 & 6,43 & 7,48 \\
\hline Nova Bassano & 5.86 & 7.43 & - & 6,65 \\
\hline Paraí & 7.00 & 7.00 & 9,14 & 7,71 \\
\hline Ipê & 7.29 & 8.00 & 8,86 & 8,05 \\
\hline Nova Arraçá & 7.57 & 7.71 & 9,43 & 8,24 \\
\hline Cotiporã & 8.00 & 7.43 & 10,00 & 8,48 \\
\hline Nova Roma do Sul & 7.71 & 7.57 & 8,57 & 7,95 \\
\hline Campestre da Serra & 4.86 & 7.00 & 10,00 & 7,29 \\
\hline Vila Flores & 7.14 & 7.14 & 10,00 & 8,09 \\
\hline Boa Vista do Sul & 6.86 & 6.43 & 9,00 & 7,43 \\
\hline São Jorge & 6.00 & 7.71 & 8,86 & 7,52 \\
\hline Monte Belo do Sul & 5.29 & 7.14 & - & 6,22 \\
\hline Fagundes Varela & 7.43 & 7.71 & - & 7,57 \\
\hline Nova Pádua & 7.14 & 7.71 & 6,00 & 6,95 \\
\hline São Valentim do Sul & 6.14 & 7.43 & 8,57 & 7,38 \\
\hline Protásio Alves & 6.57 & 7.71 & 8,57 & 7,62 \\
\hline Coronel Pilar & 6.29 & 7.00 & 7,57 & 6,95 \\
\hline Santa Tereza & 4.43 & 7.71 & 9,86 & 7,33 \\
\hline Guabiju & 6,86 & 8.00 & 10,00 & 8,29 \\
\hline Vista Alegre do Prata & 7.71 & 8.00 & - & 7,86 \\
\hline Montauri & 7.57 & 7.29 & - & 7,43 \\
\hline União da Serra & 6.29 & 7.57 & 8,57 & 7,48 \\
\hline Média & 7,06 & 7,65 & 8,60 & 7,70 \\
\hline
\end{tabular}

Fonte: Elaborado pelos autores

As questões para a análise foram elaboradas com base em Kuan, Bock e Vathanophas (2008) e tratam sobre se as informações divulgadas nos sites são integras e confiáveis, atualizadas, detalhadas o suficiente para facilitar o entendimento por parte do cidadão, se as principais informações e serviços para os cidadãos, como o portal de transparência, são de fácil acesso, se são suficientes para atender as necessidades dos cidadãos; se são úteis e se o site possui uma apresentação visual clara, que facilita a localização e compreensão.

Pode-se observar que a média geral das avaliações foi de 7,70, bem próxima a média da avaliação do profissional de Tecnologia da Informação independente. Enquanto que a média de avaliação dos autores ficou 1,54 pontos abaixo da média dos profissionais de Tecnologia da Informação de cada município estudado. Note-se que alguns profissionais de Tecnologia da Informação dos municípios não responderam à pesquisa, sendo estes ignorados para fins de composição das médias.

O município de Carlos Barbosa foi o que apresentou menor diferença entre as avaliações. Flores da Cunha, Farroupilha, Veranópolis e Guaporé também apresentaram diferenças pequenas, todos esses dentre os dez municípios mais populosos da Serra Gaúcha. As maiores diferenças encontradas foram nos municípios de Santa Tereza e Campestre da Serra. 
Já com relação às questões avaliadas, as médias ficaram entre 7,44 e 8,20, a mais baixa para a atualização das informações e a mais alta para a que avaliava se as principais informações e serviços para os cidadãos são de fácil acesso. As médias por avaliação seguiram o padrão dos municípios, com as menores médias dadas pela avaliação dos autores e as maiores pelos profissionais dos municípios, porém as diferenças não foram tão relevantes, a maior diferença encontrada foi na questão sobre as informações serem íntegras e confiáveis.

\subsection{Análises da divulgação da remuneração dos servidores}

\subsubsection{Informações da remuneração}

Os sites dos municípios da Serra Gaúcha foram acessados pela ordem decrescente de população. As informações da remuneração foram buscadas no link Portal de Transparência, ou outros que remetessem ao referido conteúdo. Assim, cada site foi analisado individualmente, inicialmente quanto às principais informações e os dados encontrados são apresentados no Quadro 2.

Quadro 2: Principais informações salariais divulgadas pelos municípios da Serra Gaúcha 


\begin{tabular}{|c|c|c|c|c|c|c|c|c|c|}
\hline \multirow[b]{2}{*}{$\begin{array}{c}\text { Tipo de Informacões: } \\
\text { Municipios } \\
\end{array}$} & \multicolumn{9}{|c|}{ INFORMACÕOES BÁSICAS } \\
\hline & 兽 & 율 & 옹 & $\begin{array}{l}\text { 을 } \\
\text { 틀 } \\
\text { 흥 }\end{array}$ & 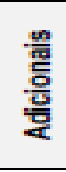 & 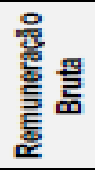 & $\begin{array}{l}\text { 을 } \\
\text { 엻 }\end{array}$ & 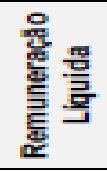 & TOTAL \\
\hline Caxias do Sul & $x$ & $x$ & $x$ & $x$ & & & & & 4 \\
\hline Bento Gonçalves & $x$ & $\times$ & $x$ & $x$ & & & & & 4 \\
\hline Farroupilha & $x$ & & $x$ & $x$ & & & & & 3 \\
\hline Garibaldi & & & $x$ & $x$ & & & & & 2 \\
\hline Flores da Cunha & & & $x$ & & $\mathrm{x}$ & $x$ & $x$ & $x$ & 5 \\
\hline Carlos Barbosa & $x$ & & $x$ & $x$ & $\mathrm{x}$ & $x$ & $x$ & $x$ & 7 \\
\hline Nova Prata & $\mathrm{x}$ & & $x$ & $x$ & $x$ & $x$ & $x$ & $x$ & 7 \\
\hline Guaporé & $x$ & $x$ & $x$ & $x$ & $x$ & $x$ & $x$ & $x$ & 8 \\
\hline Veranópolis & $x$ & $x$ & $x$ & $x$ & & & & & 4 \\
\hline São Marcos & & & $x$ & & $\mathrm{x}$ & $x$ & $x$ & $x$ & 5 \\
\hline Serafina Corrêa & $x$ & & $x$ & $x$ & $\mathrm{x}$ & & & & 4 \\
\hline Antônio Prado & $x$ & $x$ & $x$ & $x$ & $\mathrm{x}$ & $x$ & $x$ & $x$ & 8 \\
\hline Nova Bassano & & & $x$ & $x$ & $\mathrm{x}$ & & & & 3 \\
\hline Paraí & $x$ & & $x$ & $x$ & & & & & 3 \\
\hline Ipê & $x$ & $\times$ & $x$ & $x$ & $x$ & $x$ & $x$ & $x$ & 8 \\
\hline Nova Araçá & $x$ & & $x$ & $x$ & $\mathrm{x}$ & & $x$ & $x$ & 6 \\
\hline Cotiporã & $\mathrm{x}$ & & $x$ & $x$ & $x$ & & & & 4 \\
\hline Nova Roma do Sul & $x$ & & $x$ & $x$ & $x$ & $x$ & & $x$ & 6 \\
\hline Campestre da Serra & & & $x$ & $x$ & $\mathrm{x}$ & $x$ & & & 4 \\
\hline Vila Flores & & & $x$ & $x$ & & & & & 2 \\
\hline Boa Vista do Sul & & & & & & & & & 0 \\
\hline São Jorge & $x$ & $x$ & $x$ & $x$ & & $x$ & $x$ & $x$ & 7 \\
\hline Monte Belo do Sul & $\mathrm{x}$ & & $x$ & $x$ & $\mathrm{x}$ & & $x$ & $x$ & 6 \\
\hline Fagundes Varela & & & $x$ & $x$ & $x$ & & & & 3 \\
\hline Nova Pádua & $x$ & & $x$ & $x$ & $\mathrm{x}$ & $x$ & $x$ & $x$ & 7 \\
\hline São Valentim do Sul & $x$ & $x$ & $x$ & $x$ & & & & & 4 \\
\hline Protásio Alves & $x$ & $x$ & $x$ & $x$ & & & & & 4 \\
\hline Coronel Pilar & $\mathrm{x}$ & & $x$ & $x$ & & & & & 3 \\
\hline Santa Tereza & $x$ & & $x$ & $x$ & $\mathrm{x}$ & & $x$ & $x$ & 6 \\
\hline Guabiju & $\mathrm{x}$ & $x$ & $x$ & $x$ & & & & & 4 \\
\hline Vista Alegre do Prata & & & & & & & & & o \\
\hline Montauri & $\mathrm{x}$ & & $x$ & $x$ & & & & & 3 \\
\hline Uniäo da Serra & $x$ & $\times$ & $x$ & $x$ & $\mathrm{x}$ & $x$ & $x$ & $x$ & 8 \\
\hline TOTAL & 24 & 11 & 31 & 29 & 18 & 12 & 13 & 14 & 152 \\
\hline
\end{tabular}

Fonte: Elaborado pelos autores

Note-se que não foram encontradas informações referentes aos salários nos sites das prefeituras dos municípios de Boa Vista do Sul e Vista Alegre do Prata, o que prejudica o direito de acesso à informação previsto na legislação. Assim, dos 31 municípios restantes, todos divulgam a informação sobre os cargos, 29 divulgam o valor dos vencimentos, ou seja, o salário base contratual, e 24 publicam o nome dos servidores. As outras informações são menos divulgadas, apenas 11 sites possuem dados sobre o local de trabalho dos servidores, 12 sobre a remuneração bruta, 13 sobre os descontos, 14 sobre a remuneração líquida e 18 sobre os adicionais.

Dos 33 municípios, apenas 4 divulgam todas as informações básicas que compõem os salários, que são: Guaporé, Antônio Prado, Ipê e União da Serra. Contudo, é importante ressaltar também que os sites de Carlos Barbosa, Nova Prata e Nova Pádua, só não divulgaram os dados sobre a lotação dos servidores e São Jorge só não divulgou os adicionais, ou seja, publicam 7 dos 8 itens avaliados.

Apesar da importância dessas informações, ainda são superficiais considerando todos os itens que compreende a remuneração. Com relação à divulgação do nome do servidor, apesar da exposição causada ao funcionário, tem se tornado cada vez mais comum, como se observa nos municípios da Serra Gaúcha, devido, principalmente, às decisões do STF. Muitos municípios divulgam informações adicionais que tornam os dados publicados mais confiáveis e completos. Essas informações estão publicadas nos sites dos municípios conforme demonstra o Quadro 3 a seguir. 
Quadro 3: Informações salariais extras divulgadas pelos municípios da Serra Gaúcha

\begin{tabular}{|c|c|c|c|c|c|c|c|}
\hline $\begin{array}{c}\text { Tipo de } \\
\text { Informagöes: }\end{array}$ & & & & AAC & XTR & & \\
\hline Municípios & 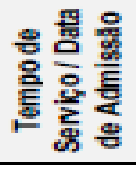 & $\begin{array}{l}\text { 哭 } \\
\text { 竎 } \\
\text { 觉 }\end{array}$ & $\begin{array}{l}\text { 옳 } \\
\text { 휴 } \\
\text { 흉 } \\
\text { 은 }\end{array}$ & 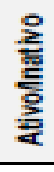 & 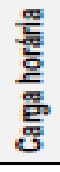 & $\begin{array}{l}\text { 윤 } \\
\text { 总 }\end{array}$ & TOTAL \\
\hline Caxias do Sul & $x$ & & $x$ & & $x$ & & 3 \\
\hline Bento Gonçalves & & $x$ & $x$ & $x$ & & & 3 \\
\hline Farroupilha & $x$ & $\mathrm{x}$ & & & & & 2 \\
\hline Garibaldi & & & & & $x$ & $x$ & 2 \\
\hline Flores da Cunha & $x$ & $\times$ & & $x$ & & & 3 \\
\hline Carlos Barbosa & $x$ & & & $x$ & $x$ & & 3 \\
\hline Nova Prata & $x$ & & & & $x$ & & 2 \\
\hline Guaporé & & & $x$ & $x$ & & & 2 \\
\hline Veranópolis & & & $x$ & & & $x$ & 2 \\
\hline São Marcoos & $x$ & $\mathrm{x}$ & $x$ & & & & 3 \\
\hline Serafina Corrêa & $x$ & $x$ & & & $x$ & $x$ & 4 \\
\hline Antônio Prado & $x$ & $x$ & & & & & 2 \\
\hline Nova Bassano & & & & & & $x$ & 1 \\
\hline Paraí & & $x$ & $x$ & $x$ & & & 3 \\
\hline Ipê & $x$ & $x$ & $x$ & $x$ & $x$ & & 5 \\
\hline Nova Araçá & $x$ & & & & & & 1 \\
\hline Cotiporã & $x$ & & $x$ & & & $x$ & 3 \\
\hline Nova Roma do Sul & & $x$ & & $x$ & & & 2 \\
\hline Campestre da Serra & $x$ & $x$ & & & $x$ & $x$ & 4 \\
\hline Vila Flores & & & $x$ & & & & 1 \\
\hline Boa Vista do Sul & & & & & & & 0 \\
\hline São Jorge & & $x$ & $x$ & & & & 2 \\
\hline Monte Belo do Sul & $x$ & & & & $x$ & & 2 \\
\hline Fagundes Varela & & & & & & $x$ & 1 \\
\hline Nova Pádua & $x$ & & & & $x$ & & 2 \\
\hline São Valentim do Sul & & $x$ & & & & & 1 \\
\hline Protásio Alves & & $x$ & $x$ & & & & 2 \\
\hline Coronel Pilar & & & & & & $x$ & 1 \\
\hline Santa Tereza & $x$ & & & & $x$ & & 2 \\
\hline Guabiju & & $x$ & $x$ & & & & 2 \\
\hline Vista Alegre do Prata & & & & & & & 0 \\
\hline Montauri & & $x$ & $x$ & & & & 2 \\
\hline Uniäo da Serra & & & & & & & 0 \\
\hline TOTAL & 15 & 15 & 13 & 7 & 10 & 8 & 0 \\
\hline
\end{tabular}

Fonte: Elaborado pelos autores

Dos 31 municípios que divulgaram informações sobre a remuneração, 15 divulgam o tempo de serviço ou a data de admissão, que contribuem, por exemplo, para a identificação de diferenças por adicionais de tempo de serviço em funcionários de mesmo cargo. Também são 15 os sites que divulgam o número da matrícula dos servidores, desses, Campestre da Serra, São Marcos e Flores da Cunha divulgam a matrícula em detrimento da publicação dos nomes dos servidores servindo como forma de identificador. Ainda há 13 municípios que divulgam o tipo de cargo, 10 que apresentam informações sobre a carga horária, 8 divulgam o padrão e são 7 os municípios que diferenciam servidores em atividade dos inativos.

Nenhum dos 31 municípios divulga todas as informações extras propostas pela legislação pertinente , mas o site de Ipê só não publica os padrões referentes a cada cargo e apenas União da Serra não divulga informações extras. Outras informações ainda foram identificadas, 4 municípios publicaram os servidores que estão afastados por licenças ou férias, outros 4 divulgam as atividades desempenhadas por cada cargo. O número de cargos é divulgado também por 4 sites, Antônio Prado divulga o número de servidores ocupantes em cada cargo. O município de Caxias do Sul publica o valor máximo pago por cargo, em detrimento da publicação detalhada dos salários.

No site do município de Bento Gonçalves encontra-se ainda a informação do CPF de cada servidor, uma grave violação do direito das informações pessoais, defendido pelo STF na 
suspensão de liminar n. 630 de 30 de julho de 2012, que causa a exposição excessiva do servidor, podendo colocar em risco a sua segurança.

\subsubsection{Apresentação das Informações}

Devido à falta de um padrão imposto na legislação, as informações podem ser encontradas dispostas de maneiras diversas em cada site, dificultando a identificação por parte dos cidadãos. Inclusive, a Lei da Transparência determina que as informações devem ser atualizadas. Além disso, seria interessante que os descontos e adicionais fossem identificados separadamente por tipo. E, ainda, a fim de facilitar a comparação, as informações referentes aos salários deveriam estar dispostas no mesmo lugar em uma lista única. Os dados encontrados nos sites dos municípios estão dispostos no Quadro 4.

Percebe-se que, dos 31 sites que apresentam informações salariais, 27 divulgam esses dados dentro do link chamado "Portal de Transparência", enquanto que os outros divulgam em links como "Acesso à Informação", "Transparência Pública", "Relação de Servidores" e "Transparência". Com relação à atualização das informações, 23 dos municípios atualizam mensalmente esses dados, pois verificou-se uma divulgação atualizada das informações, mês a mês. Já, 5 municípios divulgam apenas uma relação de remunerações por ano. Além disso, o site da prefeitura de Garibaldi divulgou somente uma lista sem data, enquanto que o site do município de Nova Bassano tem apenas um Decreto de cargos e salários datado de 2013. O município de Montauri tem, em seu site, apenas informações de abril a junho de 2014.

A respeito da especificação dos adicionais e descontos, os adicionais possuem um melhor índice de divulgação, sendo 11 os municípios que fazem esse detalhamento, enquanto apenas 5 detalham os tipos e montantes dos descontos. Ainda em relação à forma de apresentação das informações, 21 municípios divulgam os dados em uma lista única, ou seja, os outros 10 municípios que publicam as remunerações, têm listas separadas. Por exemplo, uma relação com nomes e cargos e outra com cargos e salários, o que dificulta na busca, interpretação e comparabilidade dos dados.

Além disso, 20 municípios disponibilizam as informações apenas em formato “.pdf”. O site de Farroupilha oferece a opção de “.pdf” e “.rtf”, Serafina Corrêa oferece os dados em ".pdf" ou ".doc" (arquivo de texto), o município de Fagundes Varela oferece apenas em formato "xls" (planilha). Os sites de Guaporé e União da Serra geram um arquivo de extensão ". rar" (arquivo zipado), enquanto os outros 6 municípios divulgam diretamente no site.

Quadro 4: Forma de apresentação das informações salariais 


\begin{tabular}{|c|c|c|c|c|c|c|}
\hline Municípios & 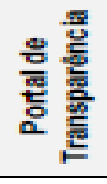 & 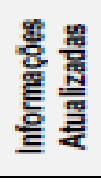 & 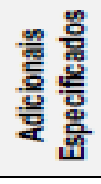 & 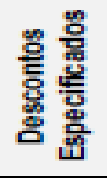 & 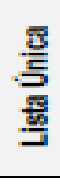 & TOTAL \\
\hline Caxias do Sul & $x$ & $x$ & $x$ & & & 3 \\
\hline Bento Goncalves & & $x$ & & & & 1 \\
\hline Farroupilha & $\mathrm{x}$ & $x$ & & & $\mathrm{x}$ & 3 \\
\hline Garibaldi & $\mathrm{x}$ & & & & & 1 \\
\hline Flores da Cunha & $x$ & $x$ & $x$ & & $x$ & 4 \\
\hline Cartos Barbosa & $\mathrm{x}$ & $x$ & $x$ & $x$ & $x$ & 5 \\
\hline Nova Prata & $x$ & $x$ & $x$ & $x$ & $x$ & 5 \\
\hline Guaporé & $\mathrm{x}$ & $x$ & & & $x$ & 3 \\
\hline Veranópolis & $x$ & & & & & 1 \\
\hline Säo Marcos & $\mathrm{x}$ & $x$ & $x$ & $x$ & $x$ & 5 \\
\hline Serafina Comêa & $\mathrm{x}$ & & $x$ & & & 2 \\
\hline Antônio Prado & $x$ & $x$ & & & $x$ & 3 \\
\hline Nova Bassano & $\mathrm{x}$ & & $x$ & & $x$ & 3 \\
\hline Paraí & $x$ & $x$ & & & & 2 \\
\hline Ipê & $\mathrm{x}$ & $x$ & $x$ & $x$ & $x$ & 5 \\
\hline Nova Araçá & $\mathrm{x}$ & $x$ & $x$ & & $\mathrm{x}$ & 4 \\
\hline Cotiporã & $x$ & $x$ & & & & 2 \\
\hline Nova Roma do Sul & $x$ & $x$ & & & $x$ & 3 \\
\hline Campestre da Serra & $x$ & $x$ & & & $\mathrm{x}$ & 3 \\
\hline Vila Flores & $\mathrm{x}$ & & & & $x$ & 2 \\
\hline Boa Vista do Sul & & & & & & 0 \\
\hline Säo Jorge & $\mathrm{x}$ & $x$ & & & $x$ & 3 \\
\hline Monte Belo do Sul & $\mathrm{x}$ & $x$ & & & $x$ & 3 \\
\hline Fagundes Varela & & & $x$ & & $x$ & 2 \\
\hline Nova Pádua & $x$ & $x$ & $x$ & $x$ & $x$ & 5 \\
\hline Säo Valentim do Sul & $\mathrm{x}$ & $x$ & & & $x$ & 3 \\
\hline Protásio Alves & $\mathrm{x}$ & $x$ & & & $x$ & 3 \\
\hline Coronel Pilar & & & & & & 0 \\
\hline Santa Tereza & & $x$ & & & $\times$ & 2 \\
\hline Guabiju & $\mathrm{x}$ & $x$ & & & & 2 \\
\hline Vista Alegre do Prata & & & & & & 0 \\
\hline Montauri & $\mathrm{x}$ & & & & & 1 \\
\hline Uniäo da Serra & $x$ & $x$ & & & $x$ & 3 \\
\hline TOTAL & 27 & 23 & 11 & 5 & 21 & 87 \\
\hline
\end{tabular}

Fonte: Elaborado pelos autores

É importante ressaltar ainda que o município de Garibaldi mantém em seu site apenas as informações dos últimos 2 meses, Flores da Cunha mantém dos últimos 3 meses e o município de Cotiporã mantém apenas do último mês. Somente 5 municípios possuem todas as características procuradas e compreendidas como ideais para facilitar o acesso e o entendimento por parte do cidadão, outros 2 apenas não divulgam os descontos especificados. Além disso, 4 deles tem apenas uma das características procuradas.

\section{Considerações finais}

A transparência das contas públicas é um tema cada vez mais divulgado e exigido pela própria população, que vai tomando consciência de sua importância. Principalmente em um ambiente de conhecidos casos de corrupção, a publicidade das informações é muito importante e com o advindo das leis de responsabilidade fiscal, transparência e acesso à informação, se tornou um direito do cidadão.

Essas informações devem ser encontradas na internet, nos sites dos órgãos públicos. Porém, para que a divulgação desses dados seja eficiente é necessário que haja um bom nível de qualidade na publicação das informações, de forma que sejam íntegras, confiáveis, atualizadas, de fácil acesso, suficientes, úteis e com apresentação visual clara para o cidadão.

Uma das informações que mais causam controvérsia no momento da divulgação é a remuneração dos servidores, especialmente com relação à publicação do nome do funcionário. Relação entre a Qualidade dos Sites das Prefeituras e o Nível de Divulgação da Remuneração dos Servidores 
Porém, conforme visto, as decisões judiciais do STF determinam a publicação nominal.

Portanto, este estudo foi conduzido com o objetivo de verificar como pode ser avaliada a qualidade das informações dos sites das prefeituras da Serra Gaúcha, especialmente em relação à divulgação da remuneração de seus servidores, a fim de analisar uma região com cidades de portes diferentes.

Com relação à qualidade das informações publicadas nos sites dos municípios da Serra Gaúcha, a avaliação com maiores médias foi a dos profissionais de Tecnologia da Informação dos municípios e as menores foram da avaliação dos autores. O município que atingiu a maior média, considerando todas as avaliações, foi Caxias do Sul com 8,62 e o de pior média foi Monte Belo do Sul com 6,22.

As médias apresentadas podem ser consideradas boas, sendo o maior problema encontrado na atualização das informações. Porém devido à importância de todas as questões abordadas, observa-se a necessidade de aprimorar as informações disponibilizadas facilitando o acesso e com informações precisas para o usuário, evitando transtornos tanto para o cidadão, quanto para a prefeitura.

No que concerne à divulgação da remuneração dos servidores, causou estranheza ainda encontrar sites municipais sem nenhum dado referente a isso, como no caso de Boa Vista do Sul e Vista Alegre do Prata. A grande maioria já publica diversos dados, inclusive o nome do servidor, de acordo com as decisões judiciais e a legislação aplicável. Observou-se que não há uma relação entre a média geral de qualidade das informações e a divulgação da remuneração dos servidores. Isto é, uma boa pontuação recebida nas avaliações da qualidade das informações não significa que o mesmo município tenha uma divulgação mais completa da remuneração dos servidores.

Entende-se que é importante divulgar o máximo de informações possíveis com relação à remuneração a fim de justificar as diferenças salariais. Contudo, os autores julgam necessário ocultar o nome do servidor, que poderia ser representado pela matrícula ou de outra forma que preserve a segurança e evite constrangimentos, assim, sendo identificável apenas em casos de dúvidas na legalidade dos dados apresentados.

Além disso, observou-se que muitos sites, especialmente os que divulgam menos itens da remuneração, apresentam grandes dificuldades no acesso das informações pela população, dividindo em diferentes listagens e oferecendo apenas uma forma de visualização com a necessidade de baixar os arquivos, além da já referida dificuldade com a atualização dos dados.

Em recente reportagem de Caio Cigana divulgada no Zero Hora no dia 20 de outubro de 2015 sobre os municípios do Rio Grande do Sul com melhores índices de transparência (CIGANA, 2015), os municípios de Ipê e Farroupilha coincidiram com boas classificações na reportagem e nesse estudo, principalmente Ipê que nessa pesquisa ficou com a melhor classificação geral com 13 itens divulgados, exibindo todos os itens avaliados na forma de apresentação e com a $11^{\mathrm{a}}$ melhor média geral de 8,05 , apenas 0,57 pontos abaixo do melhor colocado e com baixas diferenças entre as três avaliações e, segundo a reportagem, em $9^{\circ}$ dos municípios de todo o Rio Grande do Sul.

A pior colocação geral ficou com o município de Nova Bassano que divulga 4 itens da remuneração de seus servidores e se enquadra em 3 dos itens da forma de apresentação, ficou com a segunda pior média de 6,65 contando apenas com a avaliação dos autores e do profissional de Tecnologia da Informação independente.

Com relação ao porte das cidades analisadas, verificou-se que tanto na qualidade das informações dos sites, quanto na divulgação da remuneração dos servidores, a maioria dos municípios com maiores populações apresentaram melhores avaliações. Contudo, apesar dessas cidades serem mais visadas, as diferenças para os municípios de menor porte não foram muito significativas. 
No que diz respeito às limitações deste estudo, aos autores consideram interessante avaliar com maior precisão se os dados estão sendo divulgados em tempo real, conforme determina a lei, o que demonstraria melhor as dificuldades com a atualização das informações encontradas na pesquisa.

Além das comparações com a população de cada município, seria pertinente também a relação com a renda per capita de cada cidade da Serra Gaúcha e apresentar as correlações existentes em todas as etapas do estudo. As limitações encontradas podem servir também como sugestões de pesquisas futuras e, além disso, recomenda-se comparações com outras regiões do país a fim de verificar se os dados encontrados têm o mesmo comportamento dos identificados nesse estudo.

\section{Referências}

AUNE - Aglomeração Urbana do Nordeste. Região do Corede Serra: Mapeamento do Uso e Cobertura do Solo e Classificação Semidetalhada dos Solos. 2015. Disponível em:

$<$ http://www.aune.rs.gov.br/downloads/planejamento_regional/corede_solos/>. Acesso em: 15 mar. 2015.

BOZZETTO, ROBERTO ADIL. A divulgação nominal da remuneração dos servidores públicos à luz dos princípios constitucionais da publicidade e da inviolabilidade da intimidade e da vida privada: uma análise da Lei 12.527/2011 e da sua regulamentação pelo Decreto 7.724/11 e pela Resolução ${ }^{\circ} 151$ do Conselho Nacional de Justiça. Rev. de Doutrina da $4^{\mathbf{a}}$ Região, Porto Alegre, n. 58, fev. 2014.

BRASIL. Constituição da República Federativa do Brasil de 1988. Disponível em: <http://www.planalto.gov.br/ccivil_03/constituicao/constituicao.htm>. Acesso em: 01 mai. 2015.

BRASIL. Decreto n. 7.724, de 16 de maio de 2012. Regulamenta a Lei no 12.527, de 18 de novembro de 2011, que dispõe sobre o acesso a informações previsto no inciso XXXIII do caput do art. 5o, no inciso II do § 3o do art. 37 e no $\S 20$ do art. 216 da Constituição.

Disponível em: <http://www.planalto.gov.br/ccivil_03/_ato20112014/2012/decreto/d7724.htm>. Acesso em: 01 mai. 2015.

BRASIL. Lei Complementar n. 101, de 04 de maio de 2000. Estabelece normas de finanças públicas voltadas para a responsabilidade na gestão fiscal e dá outras providências. Disponível em: <http://www.planalto.gov.br/ccivil_03/leis/lcp/lcp101.htm> Acesso em: 12 mar. 2015.

BRASIL. Supremo Tribunal Federal. Suspensão de Liminar n. 630-RS. Município de Porto Alegre, Juiz de Direito da $4^{\mathrm{a}}$ Vara da Fazenda Pública do Foro Central de Porto Alegre e Tribunal de Justiça do Estado do Rio Grande do Sul. Relator: Ministro Ayres Britto. DJ, 30 jul. 2012. Disponível em:

<http://www.stf.jus.br/arquivo/cms/noticiaNoticiaStf/anexo/SL630.pdf>. Acesso em: 03 mai. 2015.

CASALINO, NUNZIO; BUONOCORE, FILOMENA; ROSSIGNOLI, CECILIA;

RICCIARDI, FRANCESCA. Transparency, openness and knowledge sharing for rebuilding and strengthening government institutions. In: WBE 2013 conference, IASTED-ACTA Press Zurich, Innsbruck, Austria. 2013.

CERVO, AMADO LUIZ; BERVIAN, PEDRO ALCINO. Metodologia Científica. 5. ed. São Paulo: Prentice Hall, 2002. 
CIGANA, CAIO. Transparência atinge só $15 \%$ das prefeituras gaúchas. Zero Hora. Porto Alegre, 20 out. 2015. Disponível em:

$<$ http://zh.clicrbs.com.br/rs/noticias/noticia/2015/10/transparencia-atinge-so-15-dasprefeituras-gauchas-4883007.html>. Acesso em 21 out. 2015

CNJ - CONSELHO NACIONAL DE JUSTIÇA. Resolução n. 151, de 05 de julho de 2012. Altera a redação do inciso VI do artigo $3^{\circ}$ da Resolução n. 102, de 15 de dezembro de 2009, do Conselho Nacional de Justiça. Disponível em:

<http://www.cnj.jus.br/files/atos_administrativos/resoluo-n151-05-07-2012-presidncia.pdf>. Acesso em: 01 mai. 2015.

COIMBRA, DAVID. O salário público dos servidores. Zero Hora, 13 jul. 2012. Disponível em: <http://wp.clicrbs.com.br/davidcoimbra/2012/07/13/o-salario-publico-dosservidores/?topo=13,1,1,,,13>. Acesso em 29 mar. 2015

CORDIS, ADRIANA S.; WARREN, PATRICK L. Sunshine as disinfectant: The effect of state Freedom of Information Act laws on public corruption. Journal of Public Economics, v. 115, p. 18-36, 2014.

CORREIO DO POVO. Acesso à Informação soma 18 mil pedidos em três anos. Porto Alegre, 16 mai. 2015. Disponível em: <http://www.correiodopovo.com.br/Noticias/556537/Acesso-aInformacao-soma-18-mil-pedidos-em-tres-anos>. Acesso em 21 mai. 2015

CRAVEIRO, GISELE. Acesso aos dados não é completo. Jornal Pioneiro, p.19, 11 jun. 2015.

CRUZ, FLÁVIO DA (coord.); VICCARI JUNIOR, Adauto; GLOCK, José Osvaldo, HERZMANN, Nélio; TREMEL, Rosângela. Lei de Responsabilidade Fiscal Comentada: Lei Complementar No 101, de 4 de Maio de 2000. 9. ed. São Paulo: Atlas, 2014.

FOINA, PAULO ROGÉRIO. Tecnologia de informação: planejamento e gestão. 3. ed. São Paulo: Atlas, 2013.

GIL, ANTÔNIO CARLOS. Como elaborar projetos de pesquisa. 5. ed. São Paulo: Atlas, 2010.

GOMES, FÁBIO BELLOTE. Elementos de Direito Administrativo. 2 ed. São Paulo: Saraiva, 2012.

GONÇALVES, ROSANA C. M. GRILLO; RICCIO, EDSON LUIZ. Sistemas de informação: ênfase em controladoria e contabilidade. São Paulo: Atlas, 2009.

IBGE - Instituito Brasileiro de Geografia e Estatística. Rio Grande do Sul - RS. 2010. Disponível em:

<http://www.cidades.ibge.gov.br/download/mapa_e_municipios.php?lang=\&uf=rs>. Acesso em: 11 ago. 2015.

KÖCHE, JOSÉ CARLOS. Fundamentos de Metodologia Científica: teoria da ciência e iniciação à pesquisa. 27. ed. Petrópolis: Vozes, 2010.

KUAN, H. H.; BOCK, G. W.; VATHANOPHAS, V. Comparing the effects of website quality on customer initial purchase and continued purchase at e-commerce websites.

Behaviour \& Information Technology, v. 27, n. 1, p. 3-16, 2008.

LOUREIRO, LUIZ GUILHERME. Registros Públicos: Teoria e prática. 3. ed. São Paulo: Método, 2012.

MARCONI, MARINA DE ANDRADE; LAKATOS, EVA MARIA. Fundamentos de metodologia científica. 7. ed. São Paulo: Atlas, 2010.

Biasio, R.; Eckert, A.; Mecca, M. S.; Toniolli, T. M. 
MARION, José Carlos; DIAS, Reinaldo; TRALDI, Maria Cristina; MARION, Marcia Maria Costa. Monografia para os Cursos de Administração, Contabilidade e Economia. 2. ed. São Paulo: Atlas, 2010.

MATOS, NYALLE BARBOZA; SILVA, MAURÍCIO CORRÊA DA; SILVA, JOSÉ DIONÍSIO GOMES DA; SOUZA, LINCOLN MORAES DE SOUZA. Avaliação de Portais de Transparência dos 30 Municípios Mais Populosos da Região Nordeste. Rev. Registro Contábil, Maceió, v. 4, n. 2, fev. 2013.

MENDES, GILMAR FERREIRA. Arts. 48 a 59. In: MARTINS, IVES GANDRA DA SILVA; NASCIMENTO, CARLOS VALDER DO (Orgs.). Comentários à Lei de Responsabilidade Fiscal. 6. ed. São Paulo: Saraiva, 2012.

MENDES, GILMAR FERREIRA; BRANCO, PAULO GUSTAVO GONET. Curso de direito constitucional. 9. ed. rev. atual. São Paulo: Saraiva, 2014.

MENDONÇA, ANA PAULA BERNARDO; PEREIRA NETO, André. Critérios de avaliação da qualidade da informação em sites de saúde: uma proposta. Revista Eletrônica de Comunicação, Informação \& Inovação em Saúde, v. 9, n. 1, 2015.

MINAYO, MARIA CECÍLIA DE SOUZA (Org.); DESLANDES, SUELY FERREIRA; CRUZ NETO, OTÁVIO; GOMES, ROMEU. Pesquisa Social: Teoria, método e criatividade. 21. ed. Petrópolis: Vozes, 2002.

NASCIMENTO, CARLOS VALDER DO. Arts. $1^{\circ}$ a 17. In: MARTINS, IVES GANDRA DA SILVA; NASCIMENTO, CARLOS VALDER DO (Orgs.). Comentários à Lei de Responsabilidade Fiscal. 6. ed. São Paulo: Saraiva, 2012.

PEREIRA, FÁBIO SOARES. A Divulgação Nominal da Remuneração dos Agentes Públicos - Um conflito entre o direito à privacidade e o direito à informação estatal. 106f. Dissertação (Mestrado em Direito) - Pontifícia Universidade Católica do Rio Grande do Sul, Porto Alegre. 2014.

PLATT NETO, ORION AUGUSTO; CRUZ, FLÁVIO DA; ENSSLIN, SANDRA ROLIM; ENSSLIN, Leonardo. Publicidade e Transparência das Contas Públicas: obrigatoriedade e abrangência desses princípios na administração pública brasileira. Contabilidade Vista \& Revista, v. 18, n. 1, p. 75-94, 2007.

RAMOS, ANDRÉ DE CARVALHO. Curso de Direitos Humanos. 1. ed. São Paulo: Saraiva, 2014.

RAUPP, FABIANO MAURY; BEUREN, ILSE MARIA. Metodologia da Pesquisa Aplicável às Ci-ências Sociais. In: BEUREN, ILSE MARIA (Org.); LONGARAY, ANDRÉ ANDRADE; RAUPP, FABIANO MAURY; SOUSA, MARCO AURÉLIO BATISTA DE; COLAUTO, ROMUALDO DOUGLAS; PORTON, ROSIMERE ALVES DE BONA. Como Elaborar Trabalhos Monográficos em Contabilidade: Teoria e Prática. 3. ed. São Paulo: Atlas, 2013.

REVISTA VEJA. Supremo libera divulgação dos salários de servidores. São Paulo, 11 jul. 2012. Disponível em: <http://veja.abril.com.br/noticia/brasil/supremo-libera-divulgacao-dossalarios-de-servidores $>$. Acesso em 29 mar. 2015

ROESCH, SYlVIA MARIA AZEVEDO. Projetos de Estágio e de Pesquisa em Administração: guia para estágios, trabalhos de conclusão, dissertações e estudos de caso. 3 . ed. São Paulo: Atlas, 2013. 
ROGERS, PABLO; SENA, LUDIANY BARBOSA. Análise Agregada dos Municípios Mineiros de Grande Porte Quanto à Adequação à Lei de Responsabilidade Fiscal (LRF). Revista Contemporânea de Contabilidade, v.1, n. 8, p. 99-119, 2007.

SACRAMENTO, ANA RITA SILVA; PINHO, JOSÉ ANTÔNIO GOMES. Transparência na Administração Pública: o que Mudou Depois da Lei de Responsabilidade Fiscal? Um Estudo Exploratório em Seis Municípios da Região Metropolitana de Salvador. Revista de Contabilidade da UFBA, v. 1, n.1, p. 1-16, 2007.

SILVA, MARIA PAULA ALMADA; CARREIRO, RODRIGO. A qualidade da informação pública: uma análise do grau de transparência dos portais de cinco estados brasileiros.

Comunicologia - Revista de Comunicação e Epistemologia da Universidade Católica de Brasília, v. 6, n. 2, p. 3-24, 2014.

TURBAN, EFRAIM; VOLONINO, LINDA. Tecnologia da Informação para Gestão: em Busca de um Melhor Desempenho Estratégico e Operacional. 8 ed. São Paulo: Bookman, 2013.

VEGA, MARCELA ESCANDON; BERNAL, LINA VELASQUEZ. Accountability social en Colombia: oferta institucional y demanda ciudadana. Revista Colombia Internacional, n. 83, p. 269-294, 2015.

VELOSO, CARLOS MÁRIO DA SILVA. A Ética na Administração Pública, na Política e nas Empresas Privadas. In: LEAL, Pastora do Socorro Teixeira. Direito Civil Constitucional e outros Estudos em Homenagem ao Prof. Zeno Veloso. São Paulo: Método, 2014.

YIN, ROBERT K.. Estudo de Caso: Planejamento e Métodos. 5. ed. Porto Alegre: Bookman, 2015. 